\title{
Practical Exploration on Setting of Teaching Course for Psychological Health Activities in Vocational Colleges \\ -- Take “Happy Classroom” Activity Teaching Course as an Example \\ Li Wang \\ Ningbo of Health Sciences College, Ningbo 315100, China
}

\begin{abstract}
This paper takes positive psychology as value idea and takes the setting of "Happy Classroom” activity teaching course of happy education of one vocational college as main line to carry out discussion from perspective of idea objective, content design, specific implementation, practical achievement, an enlightenments of setting of teaching course for psychological health activities in vocational colleges for the purpose of exploring effective means of psychological health education course reform in vocational colleges.
\end{abstract}

Key words: activity teaching; psychological health course; happy; positive psychology

\section{Background and significance}

The activity teaching mainly refers to a kind of new teaching view and teaching form which takes constructing students-oriented activities with educational, creative, practical, and operational property as main form, takes encouraging students' active participation, active exploration, active thinking, and active practice as basic feature, and takes promoting improvement of students' overall quality as purpose. ${ }^{[1]}$ The Psychological Health of College Students course not only lets students master basic knowledge of psychological health, but also lets students able to apply psychological skills into daily life, thus the students need to take experience, inspiration, operation, and practice to realize psychological growth, development, and leap. The four-dimensional integrated (“cognition, emotion, will, behavior") activity teaching is the best combination point between teachers' education and students' self-experience; through resonance of cognition and practice, and integration of practice and life, it is able to make "theoretical knowledge, practical operation, and quality training" integrated and realize three teaching objectives of course, that is, knowledge, skill, and emotion.

Our school adopt 1-credit theory teaching and 1-credit activity teaching. Through 2-year practice, the 1-credit activity teaching has formed a set of systematic "activity course", that is, it has been integrated into whole psychological health course, which makes the course become more effective and targeted and better satisfies the demand of students' self-growth. 


\section{Design and implementation}

(I) Activity teaching design concept and goal

The higher vocational sanitation colleges aim at cultivating professional talents who serve for human beings' health, and focus on how to let students full of love, fell grateful, form confident, optimistic, and sunny active attitude, use their happiness force to affect and serve others, and then do better in health service work and do a happy practitioner. Based on this, the psychological activity course of our school themes on "happiness" and takes "Happy Classroom” as platform to carry out activity-oriented happy education course. The "Happy Classroom" takes positive psychology as guide, takes "pay attention to psychological health, focus on psychological development, and improve subjective sense of happiness" as teaching concept, and takes "improve positive psychological quality, realize happy career” as overall teaching goal to enhance students' awareness of psychological health, let them learn how to adjust themselves and form confident, optimistic, and sunny positive attitude, and improve positive psychological quality through implementation of "Happy Classroom".

\section{(II) Activity teaching content design}

The research content of positive psychology mainly includes three aspects: the first one is positive experience, the second one is positive personality trait, and the third one is positive social environment. ${ }^{[4]}$ In terms of activity content and carrier design, the "Happy Classroom" integrates these three aspects of content. Especially in positive social environment, we make use of happy class culture show, "happy bedroom life” campus psychological scene play and other activities to make students find and feel happiness from the warm collective atmosphere created. According to students' psychological growth law of "cognition, emotion, will, behavior”, the "Happy Classroom" will be divided into three theme plates: "self-exploration, happy perception”, "self-practice, happy experience”, and "self-actualization, happy employment". Each theme plate includes rich and colorful activity carrier and adopts the combination of menu selection and credit system management; the students can independently select the activities they participate in based on their hobbies and interests. Through participating in and experiencing various kinds of mental activities, the students can realize a development from perceiving and accepting happiness to deeply experiencing and inspiring happiness, and then seeking for happiness from future occupation. The "Happy Classroom” is operated by use of positive psychology quality.

(III) Specific implementation of activity teaching

(1) Implementation object: freshmen and sophomore.

(2) Teaching team: The teaching team includes teachers of health theory course, counselors who are responsible for students' work and psychological health work, and partial class teachers. In addition, the peer psychological health counselors are also the important power to organize and carry out activities. Before starting of each team, the teaching team shall make a discussion on the activities of "Happy Classroom" and reach a consensus on activity implementation, credit gaining, and performance assessment according to Happy Classroom Growth Manual. 
(3) Organization and management: Firstly, the propaganda is required before implementation. In the $1^{\text {st }}$ week after the freshmen enter the school, they shall be issued with Happy Classroom Growth Manual, and the teaching team shall go to each class to interpret Happy Classroom Growth Manual. The persons in charge of course shall carry out a series of special training on peer psychological health counselors in terms of how to understand “Happy Classroom” and how to better organize activities. Secondly, the activities shall be organized and implemented well. The implementation of activities can't be separated from expenditure support and corresponding incentive mechanism. Except for special psychological health fund, the "Happy Classroom" also has the support from students career development education activity expenditure. The activities are implemented via counselors' incentive mechanism and excellent peer counselor assessment. Thirdly, the activities shall be layering. Before implementation, it is required to make clear which activities are school-level and which activities are psychological activities with professional features and determine the responsible persons. Meanwhile, the assessment standard of each activity shall be also determined.

(IV) Activity teaching examination and evaluation

The combination of process assessment and performance assessment is adopted, and more attention is paid to process assessment.

(1) Examination and evaluation on students. Each student shall complete Happy Classroom Growth Manual within two school years. The class commissary in charge of psychology shall specifically record each student's situation about participating in activities and then deliver for future approval; while the students complete 1-credit hour, they can obtain the credit in case of qualified assessment, and the assessment summary shall be submitted to psychological health guidance center. The assessment indexes include activity participation, self-adjustment ability, helping ability, students' self-assessment, students' feelings, peer assessment, and teacher evaluation for the purpose of realize diversified and objective examination and evaluation.

(2) Examination and evaluation on course. The course evaluation adopts combination of quantization and quantization. As for students' group effect, firstly, Well-Being Scale of College Students ${ }^{[4]}$ revised by Cui Chunhua is adopted to carry out test on students of 2011 session before and after implementation; there are totally 39 questions, each of which is scored as 6 points; the higher the total score is, the higher the subjective happiness is, and the highest score of overall subjective happiness is 234. The consistency of well-being scale is 0.91 . Secondly, it is required to classify and analyze the information recorded on students' growth via each student recording the Happy Classroom Growth Manual. Thirdly, the investigation and survey is made on students' satisfaction of whole source. The Happy Classroom Satisfaction Questionnaire is compiled to carry out survey for random 532 sophomore, with 527 effective questionnaire obtained.

\section{Activity teaching practice result}

(I) Students' subjective well-being is obviously improved.

Before implementation of "Happy Classroom” activity teaching classroom, the test is made for 2054 students of 
2011 session, with 1962 effective questionnaire obtained. Through statistics of overall effective questionnaire, it is obtained that the average score of subjective well-being is 154.62, and SD is 14.32. After implementation, the result shows that the average score of students' overall subjective well-being is 168.54 , and SD is 16.15 . Through matching with sample $\mathrm{T}$, it is found that there exists significant difference $(t=28.555, P<0.001)$. The testing result shows that the activity-oriented teaching course effectively improves students' subjective well-being.

(II) Students' positive psychology quality is gradually developed.

Through tracking observation method and looking students' Happy Classroom Growth Manual, we can find many students' experience and feeling to each activity, which witnesses the process of students' psychological growth. For example, after participating in practice activity of "sunshine journey of soul messenger”, a student wrote in his growth manual: "In childhood, the happiness is an easy thing; after I grow up, the simpleness is a happy thing. Each week when I go to Sangju community and teach residents to learn psychological health exercises, I feel very satisfied and happy. When I do the thing I like, the business is also a kind of happiness. For another example, after a student participated in campus psychology scene play, he expressed his feelings: through playing the role who suffers family and emotional blow and finally has a change, I understand that there always exist irresistible frustrations in our life; however, as long as we have a healthy and optimistic soul to face each frustration in our life and learn to put down and accept frustration, there will be always sunny days.” After participating in happy class culture show, a student said: "I think that I will remember happy class and a group of lovely friends in happy class forever in my life. Over two months, we cry together and simile together; despite of friction and conflicts, what we obtain is the delight after success and the happiness we witness together. As one of the organizers of this activity, from the time when I write Happy Class Contest Registration Form, I have been aware of the importance of "group" at this time; the happiness of one class is not reflected via one student's being good at singing and dancing or having the gift of gab, and the exhibition of class happiness needs our joint efforts. Everyone in the class is on the chain of happiness, and none is dispensable.”

(III) The activity teaching course is commonly accepted.

Through survey on students' satisfaction of activity teaching course, most of students approve the implementation of course. The survey result can be seen in Table 1.

Table 1. “Happy Classroom” Satisfaction Survey

Number of people (percentage)

\begin{tabular}{|l|c|c|c|c|}
\hline \multicolumn{1}{|c|}{ Content } & \multicolumn{4}{c|}{ Option } \\
\hline 1. Can you understand the content of "Happy & Completely & Basically & Not fully & No \\
Classroom” Growth Manual? & $142(26.94 \%)$ & $336(63.76 \%)$ & $49(9.30 \%)$ & 0 \\
\hline 2. Are you satisfied with the activities carried out & Very much & Relatively & Commonly & No \\
in "Happiness Classroom”? & $64(12.14 \%)$ & $422(80.08 \%)$ & $41(7.78 \%)$ & 0 \\
\hline 3. Are you interested in the activities carried out in & Very much & Relatively & Commonly & No \\
"Happiness Classroom”? & $57(10.82 \%)$ & $415(78.75 \%)$ & $54(10.25 \%)$ & $1(0.19 \%)$ \\
\hline 4. Do you think you have gained something from & Very much & Some & Commonly & No \\
the activities carried out in "Happiness & $55(10.44 \%)$ & $432(81.97 \%)$ & $40(7.59 \%)$ & 0 \\
\hline
\end{tabular}




\begin{tabular}{|c|c|c|c|c|c|c|}
\hline \multicolumn{7}{|l|}{ Classroom”? } \\
\hline $\begin{array}{l}\text { 5. Are you satisfied with psychology propaganda } \\
\text { work made by the class commissary in charge of } \\
\text { psychology? }\end{array}$ & $\begin{array}{l}\text { Very much } \\
97(18.41 \%)\end{array}$ & $\begin{array}{c}\text { Relatively } \\
\text { 274(51.99\%) }\end{array}$ & \multicolumn{2}{|c|}{$\begin{array}{c}\text { Commonly } \\
144(27.32 \%)\end{array}$} & \multicolumn{2}{|c|}{$\begin{array}{c}\text { No } \\
12(2.28 \%)\end{array}$} \\
\hline $\begin{array}{l}\text { 6. Which activity of "Happy Classroom" is most } \\
\text { popular among students? (the students fill in the } \\
\text { content according to order, and the previous } 6 \\
\text { activities are shown in table.) }\end{array}$ & $\begin{array}{l}\text { Happy class } \\
\text { culture show }\end{array}$ & $\begin{array}{l}\text { Campus psychol } \\
\text { ogical scene } \\
\text { play }\end{array}$ & $\begin{array}{c}\text { Fresh } \\
\text { men } \\
\text { outwar } \\
\mathrm{d} \\
\text { trainin } \\
\mathrm{g}\end{array}$ & $\begin{array}{c}\text { Psych } \\
\text { ologic } \\
\text { al } \\
\text { health- } \\
\text { theme } \\
\text { d class } \\
\text { meetin } \\
\text { g }\end{array}$ & $\begin{array}{c}\text { Soul } \\
\text { bar } \\
\text { work } \\
\text { shop }\end{array}$ & $\begin{array}{c}5.25 \\
\text { Ballo } \\
\text { on } \\
\text { flyin } \\
\text { g } \\
\text { activi } \\
\text { ty }\end{array}$ \\
\hline
\end{tabular}

It can be known according to the survey that most of students hold a positive and satisfied attitude toward "Happy Classroom” activity teaching and think that the "Happy Classroom” activity can help them grow up.

\section{Considerations in implementation of activity teaching course}

(I) To implement relevant guarantee conditions

There are three most important guarantee conditions in activity teaching. The first one is sufficient expenditure. The second one is teaching team. Except that the quantity and quality of teaching team shall be guaranteed, the concept shall be consistent to improve activity teaching to the level of education. The third one is the guarantee on document system. The activity teaching content system shall be clear, the management system shall be standardized, and the incentive systems related to teachers and students shall be implemented.

(II) To fully exert peer psychological counselors’ function

In the activity teaching, the peer psychological counselors are both participators, and developers and implementers of many activities. Firstly, it is required to train their psychological propaganda skills; secondly, it is required to boldly let them plan and organize activities. The teachers shall fully play the role of guiders and collaborators, fully respect and cultivate students' subjectivity, and emphasize self-education and subjective practice in activity teaching to realize "learning upon doing” and "unity of moral knowledge and practice".

(III) To design suitable teaching activity carrier

In activity teaching, the design of activity carrier shall be made based on teaching goal rather than only pay attention to the activity for the purpose of seeking for form of activity. The activity is only an external pattern of representation, and the formation of students' positive quality and psychological quality is the foothold of teaching. Therefore, in activity design, we shall always consider the purpose of activity, the psychological quality which can be cultivated for students, how to guide students to make experience and reflection in activity, whether those activities are close to students' life, and whether the students are interested in the activity. Meanwhile, we shall also consider students' individual participation and design different layers of activity carriers including exhibition activity and grass-roots activity so that each student can show themselves.

(IV) To make integration with psychological health theory course 
In terms of both teaching goal and design of teaching content, the 1-credit activity teaching shall be integrated with 1-credit theory course. While the teachers guide activity implementation, they shall effectively combine the theoretical knowledge of psychological health with the activities, and guide students to apply the psychological knowledge and skills they have learnt into activities so as to transform those skills into their own personality characteristics.

\section{Acknowledgments}

This paper is Zhejiang provincial higher education classroom teaching reform project Practical Research on Psychological Health Classroom Teaching Based on “Professional Design, Life Domination” (kg2013876).

\section{References}

[1] Sun Qifang: Design Strategy of Psychological Health Education of College Students Activity Teaching [J], Henan Education (Higher Education), 2013 (6): 66-67.

[2] Gong Xiaguang: Exploration and Application of “Three-aid” Teaching Mode - pay attention to psychological health education of college students [J], Hunan Education (I), 2012 (12): 50-51.

[3] Ren Shengtao: Enlightenments of Positive Psychology on Classroom Teaching of Psychological Health Education of College Students [J], Journal of Nanchang College of Education, 2010 (11): 128-134.

[4] Yin Qiuyun: Dislocation and Development of Psychological Health Education Course under View of Positive Psychology [J], Heilongjiang Researches on Higher Education, 2012 (12): 166 - 168.

[5] Cui Chunhua: Preliminary Study on Compilation and Reliability and Validity of Well-Being Scale of Hebei College Students [D], Shijiazhuang: Hebei Normal University, 2005. 